\title{
$02 \begin{aligned} & \text { university } \\ & \text { of the arts } \\ & \text { london }\end{aligned}$
}

\begin{tabular}{|l|l|}
\hline Title & Battle jackets, authenticity and 'material individuality' \\
\hline Type & Article \\
\hline URL & https://ualresearchonline.arts.ac.uk/id/eprint/11926/ \\
\hline Date & 2017 \\
\hline Citation & $\begin{array}{l}\text { Cardwell, Thomas (2017) Battle jackets, authenticity and } \\
\text { 'material individuality'. Metal Music Studies, 3 (3). pp. } \\
437-458 . \text { ISSN ISSN 2052-3998 (Print); ISSN 2052-4005 } \\
\text { (Online) }\end{array}$ \\
\hline Creators & Cardwell, Thomas \\
\hline
\end{tabular}

\section{Usage Guidelines}

Please refer to usage guidelines at http://ualresearchonline.arts.ac.uk/policies.html or alternatively contact ualresearchonline@arts.ac.uk.

License: Creative Commons Attribution Non-commercial No Derivatives

Unless otherwise stated, copyright owned by the author 


\title{
Battle jackets, authenticity and 'material individuality'
}

\section{Tom Cardwell}

\section{University of the Arts London}

\author{
Keywords: \\ battle jackets \\ metal \\ fandom \\ authenticity \\ identity \\ customization
}

\section{Abstract}

This article will consider the significance and meaning of battle jackets within the context of metal subcultures. Beginning with a summary of the history of the practice of customizing jackets by metal fans, ideas of personal subcultural identity and authenticity will then be used to more fully understand the importance of the jackets to those that make and wear them.

Consideration of the importance of identity in jacket making will be given in terms of David Muggleton's concept of 'distinctive individuality', whilst Sarah Thornton's 'subcultural capital' and ideas of 'insider' hierarchies will be referred to in the discussion of authenticity.

The final section will survey some of the practices of customization used by fans in constructing jackets to consider their visual and material aspects using Richard Sennett's 'material consciousness'. Following this, the term 'material individuality' is proposed to describe jacket practices through bridging the various theories discussed.

Observations are drawn from interviews with jacket wearers conducted between July 2014 and June 2015 at 'Sonisphere' and 'Bloodstock' music festivals, United Kingdom, and at the 'Modern Heavy Metal Conference 2015', Helsinki, Finland, as well as from my own experiences within metal subculture.

\section{Introduction}

A battle jacket is a customised garment worn in heavy metal subcultures that features decorative patches, band insignia, studs and other embellishments Battle jackets are significant in the expression of subcultural identity for those that wear them, and constitute a global phenomenon dating back at least to the 1970s. Whilst battle jacket making is referred to in discussions of identity in existing metal scholarship (Ferrarese, 2015, p. 200, Weinstein, 2000, p.128), there has not yet been any particular study of battle jackets 
themselves or of the practices involved in their production and use. This article draws on my own research using painting practice and interviews to better understand the significance of battle jackets within metal subcultures and in wider culture. I have made a series of paintings that document particular examples of jackets from fans that I have interviewed (see figure 1). Because battle jackets are visual garments that communicate through the images and logos they contain, visual art practice is an ideal research method. Recent scholarship has recognised the benefits of a close relationship between art practice and ethnographic research (Grimshaw and Ravetz, 2005, Grimshaw, Owen and Ravetz, 2010) finding that the disciplines can be mutually reinforcing. The artworks made during this project have been the focus of a recent exhibition (Wimbledon Space, London, 2017). Alongside the paintings, the research refers to interviews with jacket makers conducted over a two-year period.

This article will argue that battle jackets are very important within metal subculture as visual garments that display the fan's individual identity as well as adherence to tacitly agreed values within metal communities that exist both in physical space as well as online. Additionally it is suggested that battle jacket making has important connections to wider folk art and craft practices. Whilst in recent years it is increasingly common for metal styles to be appropriated as fashion, for many fans the battle jacket continues to reflect a deep lifestyle commitment to metal music and values.

\section{Interview methodology}

Interviews were conducted at two heavy metal festivals in the United Kingdom in 2014, and at one academic conference in Finland in 2015. Sonisphere festival took place on 4-6 July 2014 at Knebworth park, Hertfordshire, United Kingdom and was the largest metal-specific festival in the country that year, with a roster that included more mainstream metal bands ('Metallica' and 'Iron Maiden' headlined in 2014) and so drew a wide spectrum of fans, including some who would not consider themselves part of the metal subculture.

Bloodstock took place from 8-10 August 2014 at Catton Park, Derbyshire, United Kingdom. Bloodstock is a smaller festival which features more specialized or 'underground' acts that attract loyal followings but are often not well-known outside of the discourses of metal media and subculture (headliners in 2014 included 'Down', 'Dimmu Borgir' and 'Megadeth'). The Modern Heavy Metal Conference 2015 was an academic research conference that took place in Helsinki, Finland from 8-12 June 2015.

In total, nine interviews were conducted with eleven respondents, seven of whom were male, and four female. Subjects' ages ranged from seventeen to 50 years old. Interview duration ranged from around five minutes to over 40 minutes. Interviews were recorded and transcribed afterwards. All interviewees were informed of the purposes of the research and signed consent forms. Additionally, many more jacket wearers were spoken to in short conversations that were not recorded as interviews. Whilst these 
opinions cannot be referenced directly, they have contributed to overall conclusions. Interview subjects were selected in the first instance because they were wearing battle jackets. Initially subjects were approached and asked permission to have their jackets photographed. If they agreed to being photographed and seemed open to talk, they were then asked to participate in the interviews. The interviews were semi-structured in nature. Interviewees were allowed to follow their own trains of thought and to bring up issues they considered important. Questions were used as and when necessary.

Generally, interviews began with respondents being asked to talk about the history and construction of their jacket. Typical questions included: 'How did you select which bands to feature on your jacket?', 'How long have you been making your jacket, and do you sew it yourself?', 'How important is your jacket in displaying your identity?'.

These semi-structured interviews were used to gain an accurate record of particular fans' personal perspectives on jacket making and the role of the jacket in articulating their sense of personal and subcultural identity.

As part of the research project a series of paintings of respondents' jackets was also produced (see figure 1).

\section{The history of battle jackets}

It is difficult to say precisely when metal fans first began to customize their jackets to reflect musical tastes, as much of the history of early metal fandom was recorded anecdotally, if at all. Heavy metal as a musical genre is considered to have started somewhere between 1969 and 1972 and to have been well established by the mid 1970s (Weinstein, 2000: 14). From a number of subjects interviewed, as well as jackets in museum collections (such as that of the 'M Shed' museum in Bristol, United Kingdom), it can be estimated that by the late 1970s forms of customized jackets were being worn by metal fans. Visually, battle jackets are closely related to different variations of biker jackets used by motorcycle clubs and recreational riders. Alford and Ferriss (2007: 189) summarize the history of the biker jacket. In biker culture a number of significant traditions of jacket customization exist. Most well-known are probably the emblazoned jackets of the 'patch clubs' of which the 'Hell's Angels' are the most famous example (Alford and Ferriss, 2007: 86-87). These 'outlaw' clubs (so called due to their lack of affiliation with the American Motorcycle Association and its international counterparts) (Dulaney, 2005) observe strict order to the decoration of their jackets, which are used to identify club affiliation, geographic territory and individual role and rank within the group (Vick, 2015: 10). Such clubs formed after World War 2, and the style of customized jackets they use probably dates from that time (Vick, 2015: 10). Other traditions of customization include the elaborate embroidery of the Japanese 'Bosozoku' groups (Alford and Ferris, 2007: 72-78) and the more idiosyncratically decorated jackets of the 'rockers' and 'ton-up boys' that emerged in the 1950s in Britain (Stuart, 1987, Friedrichs, 2012). Following in 
the vein of the latter groups, many recreational bikers chose to customize their jackets with 'run patches' that commemorate specific rides and meetings.

The crossover between motorcycle culture and heavy metal is well documented. Deena Weinstein traces the origins of the subcultural style of metal emerging out of the 1960s countercultures of hippies and bikers (Weinstein, 2000: 100). A number of fans I have met are also bikers, and combine both types of iconography on their jackets (see figure 2). Pete, a band member and metal fan who began making battle jackets in the early 1980s identifies this connection explicitly:

We're talking about 1984 (when) I started doing this. There was a lot of patch jackets around, but more of them was coming from the bike side of things. I used to go underage drinking in this metal pub in Eastcote, called the Clay Pigeon [...] So this was the ultimate metal club, run by the guy who basically discovered Iron Maiden. And we all went down there and it was just wall-to-wall bikes and jackets (Pete, 2014: 1, grammar unchanged).

Another fan I interviewed also refers to the origin of battle jacket-making in biker culture: 'I know it started with biker gangs, say the Hell's Angels [...] they probably started it with their patches, and it probably just came into this community' (Chris, 2014: 4).

Early battle jackets featured hand-embroidered band logos (see figure 3), either because commercially produced patches were not yet widely available, or because the fan required a larger logo than the patches they could purchase.

By the mid 1980s metal-specific battle jackets were common amongst metal fans, many of whom had no direct connection to motorcycle culture. Whilst metal fans may also wear leather biker jackets, it is the lighter (and more easily sewn) denim jackets and vests that tend to predominate. Deena Weinstein describes the prevalence of denim:

The jeans jacket, a legacy of the hippie, is more popular than the black leather jacket in terms of prevalence. These jackets are not only far less expensive than leather, they are also light enough for summer wear. Both kinds of jacket provide spaces for an array of patches, buttons, pins, and homemade artistic efforts. (Weinstein, 2000: 128) 
Tom Cardwell, University of the Arts London

Metal Music Studies 3.3

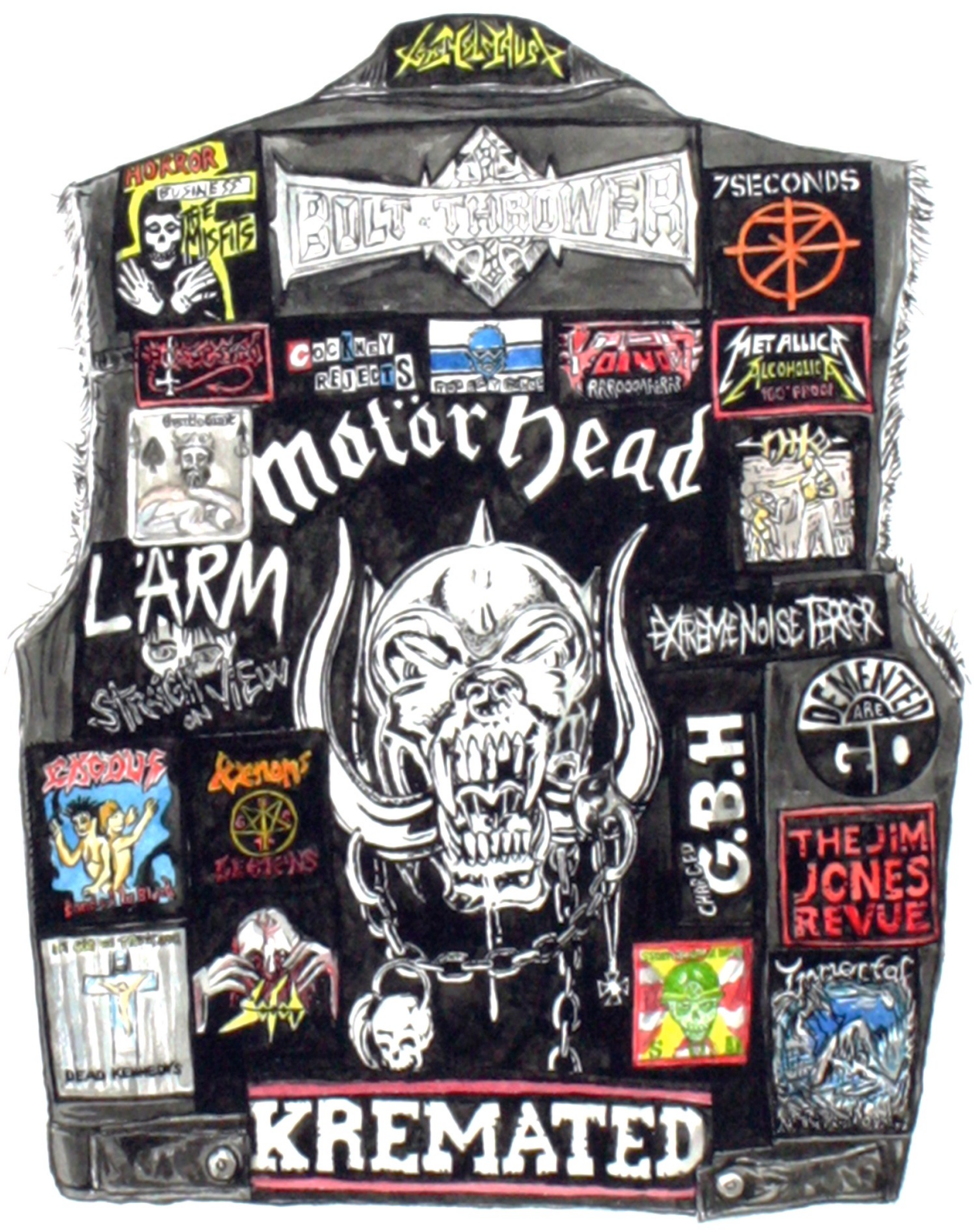

Figure 1: Tom Cardwell: Pete's Jacket, back. Watercolour on paper 38 x 26 cms, 2015. 
Tom Cardwell, University of the Arts London

Metal Music Studies 3.3

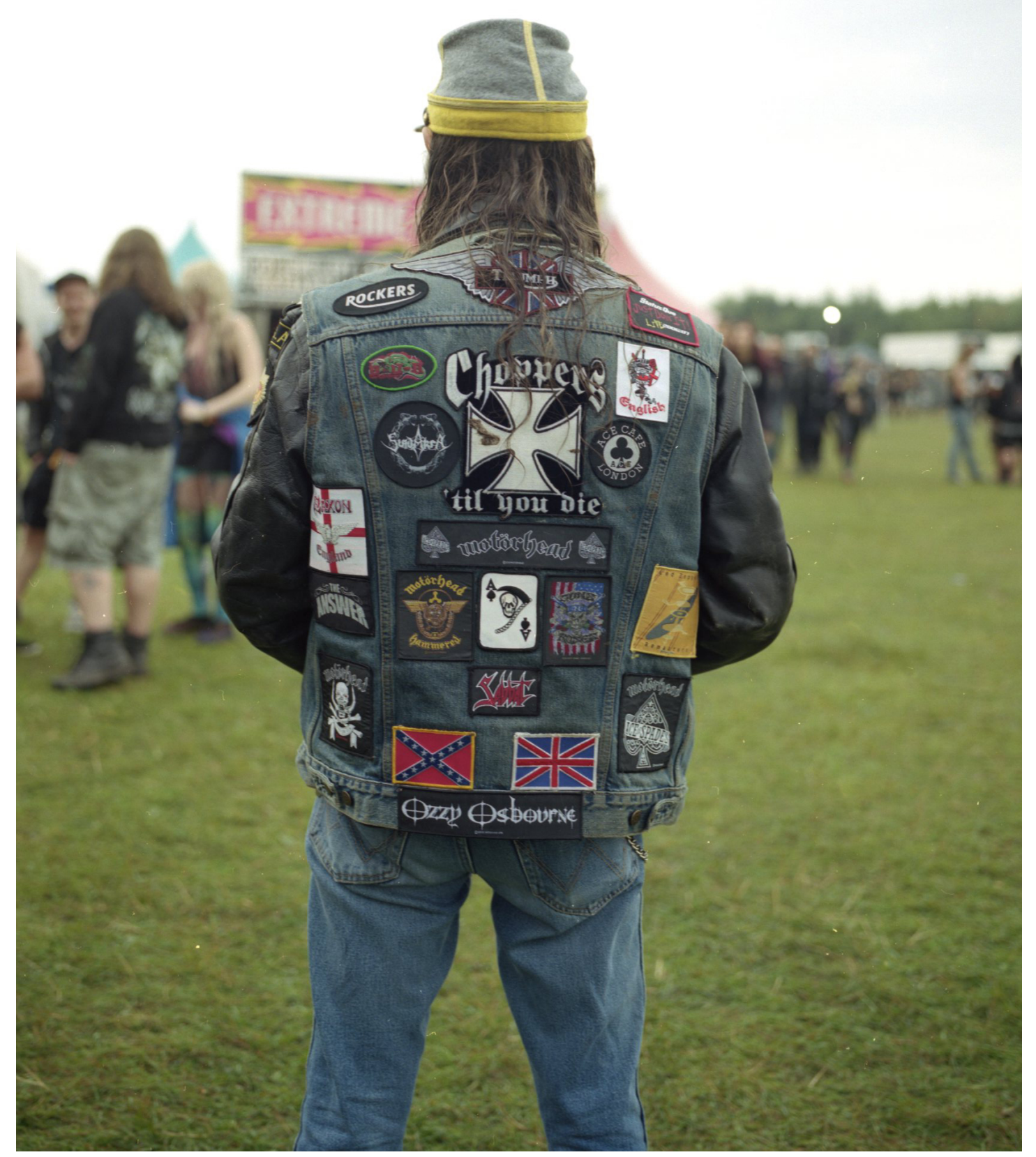

Figure 2: Jacket featuring biker patches alongside metal band logos. Bloodstock festival, Derbyshire, United Kingdom, 09.08.14. Photograph by Jon Cardwell 
If battle jackets were popular amongst metal fans in the 1980s, they were perhaps less so in the decade that followed. During the 1990s, the dominant metal styles of previous years such as 'thrash' and 'glam' metal became less fashionable within metal subcultures, giving way to new movements such as 'nu metal' and 'grunge' (Weinstein, 2000: 56-57). Battle jackets did not disappear altogether, persisting amongst emerging extreme subgenres such as 'death' (an extreme form of thrash) and 'black' (occult-influenced) metal (Stubberud, Strømmen \& Belgaux, 2016). In the decade after 2000, older styles of metal became popular again, finding new audiences and reinvigorated by the growing popularity of Scandinavian extreme and 'classic' metal. Alongside this trend, battle jacket-making surged in popularity once more. Today the practice is widespread, facilitated by the presence of numerous internet forums (see figure 4) where users can upload and discuss their jackets (see for example tshirtslayer.com). The production and consumption of band patches is also thriving, with the web making the finding and purchasing of patches much easier (see figure 5).

\section{Identity}

The communication of identity is perhaps the most fundamental symbolic function of the battle jacket to those within the subculture. Whether it is the mapping of a personal set of musical taste preferences, self-selection as a member of a particular subgenre of metal, or a stand against the perceived mainstream, almost all of the fans I have spoken to view their jacket as a way of communicating their identity in some way.

Identity is a common theme in subcultural studies, often viewed as the nexus of the relationship between the individual and social group. As long ago as 1959 psychologist Erik Erikson presented a model of individual identity aligned to the three categories of 'ego identity', 'personal identity' and 'social identity' (Erikson, 1959). Personal identity was used to describe a sense of unique individuality, whilst social identity referred to the role of relationships with other individuals and groups.

The Birmingham Centre for Contemporary Cultural Studies (CCCS) made a significant contribution to studies of subcultural identity during the 1970s and beyond. Dick Hebdige, building on earlier CCCS work, attempted to deconstruct the messages of subcultural style. Hebdige saw subcultures as arising in particular times and places, as solutions to class-based problems (Hebdige, 1979: $79 \mathrm{ff}$.). Members belonged to a social group with a collective identity, the characteristics of which were communicated through clothing and style, amongst other things (Hebdige, 1979: 100-101). J. Patrick Williams (2011) sums up this approach as 'insider/outsider' - clothing, language and behaviours are used to demarcate an individual's identity as an 'insider' in contrast to the rest of society, considered 'outsiders'. Williams illustrates this with the example of 'straightedge' music fans in the United States. He quotes a fan who posted on an internet forum about his rationale for identifying with 
straightedge lifestyle values: 'I claim straightedge because I'm smart and angry and rebellious, and I will question everything that society tries to force me to swallow' (Williams, 2011: 131). In this example, the individual contrasts their (values-based) subcultural identity with a perceived homogenous mainstream labelled 'society' against which they are antagonistic.

David Muggleton (2000) has built on the work of Hebdige, but recognizes the complexities of defining subculture in a postmodern environment. Muggleton underlines the importance of appearance in defining identity in postmodern subcultures and attempts to describe the connection between style and meaning in subcultural expression. Muggleton uses the term 'distinctive individuality' to describe the ways in which members of a subculture differentiate themselves from the rest of society, and identify as part of a particular group. One of the main ways this occurs is through clothing and style practices. Muggleton describes distinctive individuality as 'the way that subculturalists highlight their individuality through a distinction from a collective reference group, in this case, conventionally dressed people' (Muggleton, 2000: 63). He goes on to outline the tensions that exist between the willingness of subculturalists to identify with a group label (e.g. 'metalhead' or 'goth') and the postmodern tendency to navigate identity on a primarily individual basis. This can lead to an individual adopting the style of a particular subculture without necessarily identifying as a member of that group. Metal fans that I have spoken to tend to see themselves as part of metal subculture, even if this does not impact their behaviour beyond listening to metal music and going to concerts.

In her research amongst metal fans in the Czech Republic, Germany and Slovenia, Anna Baka (2015) sought to define what constitutes a 'metal identity'. She found that whilst there is some fluctuation between levels of commitment to metal subculture, metal fans comprise more of a cohesive group than might be expected from post-subcultural theories. Whilst outsiders might cast metal fans based on superficial judgements, within the scene itself 'knowledge of the in-group differentiation is generally good.[...] no sub-genre divisions seem to impair an overwhelming sense of community of all metalheads.' (Baka, 2015: 62). In other words, metal fans may be less inclined to appropriate the style of the battle jacket without a deeper commitment to the music it represents.

The battle jacket is an ideal way for a metal fan to express their distinctive individuality, to emphasize their allegiance to the subcultural group, and their distinction from mainstream culture. It shows their status as insiders to the metal scene in contrast to the outsiders of the rest of society. Additionally, for many it may also be a way of communicating, to others as well as to themselves, a sense of their own particular personality. This can be conveyed both by the choice of bands displayed on the jacket, as well as the methods of arrangement of patches, and the practices of customization. 
A metal fan called Eleanor refers to the importance of the jacket and metal style in communicating her identity: 'It's expressive. It's who you are. It's definitely important. I think we both find style quite an important thing.' (Eleanor and Jemima, 2014: 4). In Muggleton's terms, Eleanor's sense of 'who you are' could be thought of in terms of being part of the metal subculture - an insider as opposed to the outsiders of the mainstream (Muggleton, 2000: 65, Williams, 2011: 131), yet also maintaining a sense of personal expression within metal itself. What is more, this sense of identity is communicated and expressed through clothing style, amongst other things. Another fan, Paul, describes his recent decision to begin making and wearing a battle jacket in personal terms:

I never used to have one when I was young and sprightly back in the day, with long hair and all that stuff, I never had one back then. I guess, um, I thought it was too cliché I guess, back then, I was trying to be a bit different [...] I guess when you get older you don't give a shit anymore, so, I wanted a battle vest, that was it. So I went out, I got the vest (Paul, 2014: 1, grammar unchanged).

Paul recognises the sense in which a battle jacket would connect him to the wider subculture of metal fans, but paradoxically it was this sense of clear identification that prevented him from making a vest in his younger days, as he didn't want to appear 'cliché'. His later decision to make a jacket is construed in terms of a personal choice, and a desire to ignore what other fans might think. Later in the interview, Paul portrays his manner of dressing as idiosyncratic, consciously at odds with the tacitly accepted style codes of the metal scene:

But I dressed a lot differently...my hair was long and I used to dye it as black as you like, and I used to wear leather trousers. I looked like somebody from a death metal, sorry, a black metal band. But I wasn't really into black metal, but I liked the aesthetic (Paul, 2014: 2, grammar unchanged).

Paul appears to feel free to play with the stylistic codes of metal dress, and whilst he still identifies as a metal fan in a real sense, he seems to resist any perceived expectation to fit into a particular style and instead to assert his individual identity. A more marked strain of this tendency to individually mix subcultural style genres is defined by Muggleton as 'crossover' (Muggleton, 2000: 75) and can be read as a typically postmodern response to stylistic structures. 
Tom Cardwell, University of the Arts London Metal Music Studies 3.3

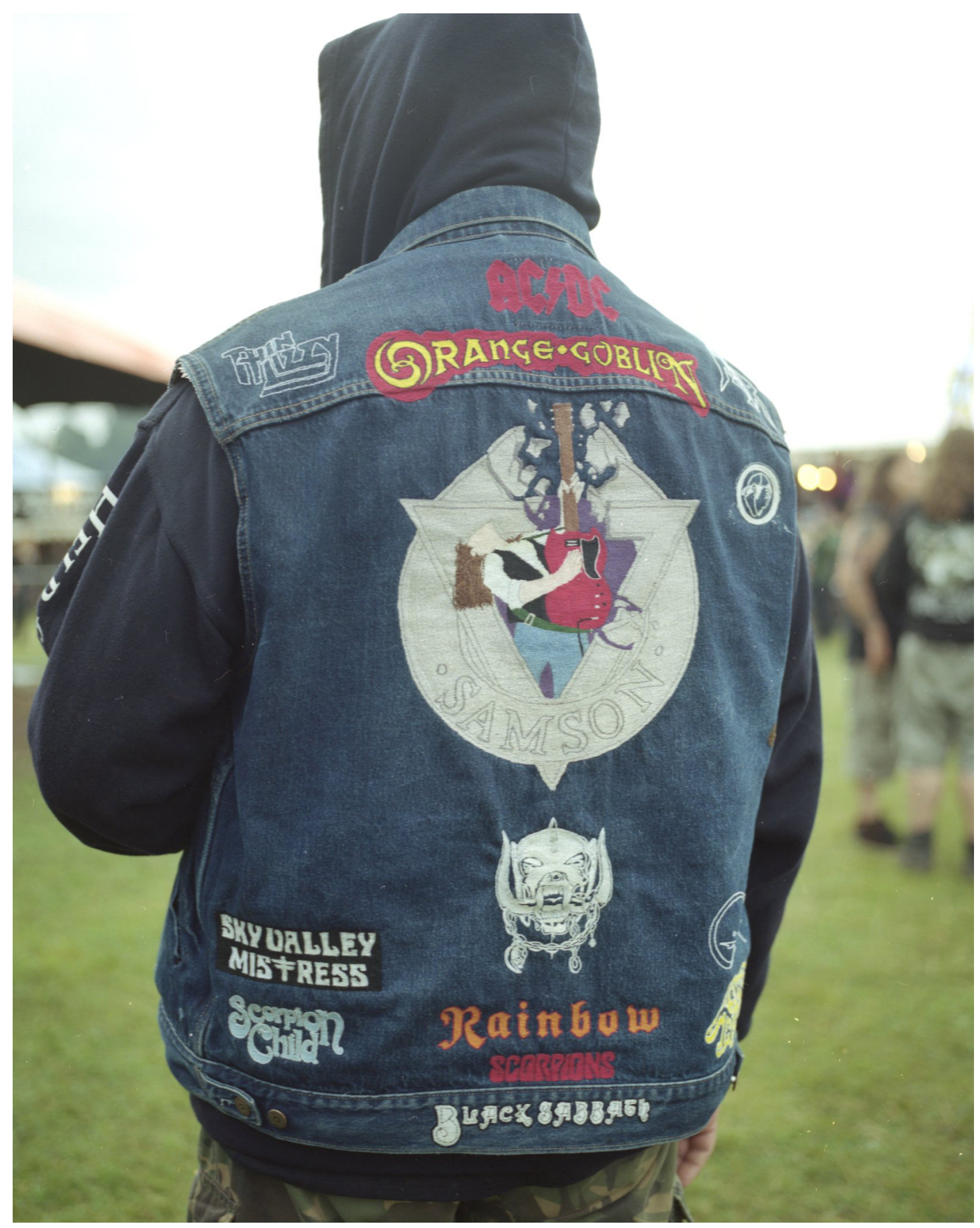

Figure 3: Jacket featuring hand-embroidered logos. Bloodstock festival, Derbyshire, United Kingdom, 09.08.14. Photograph by Tom Cardwell. 


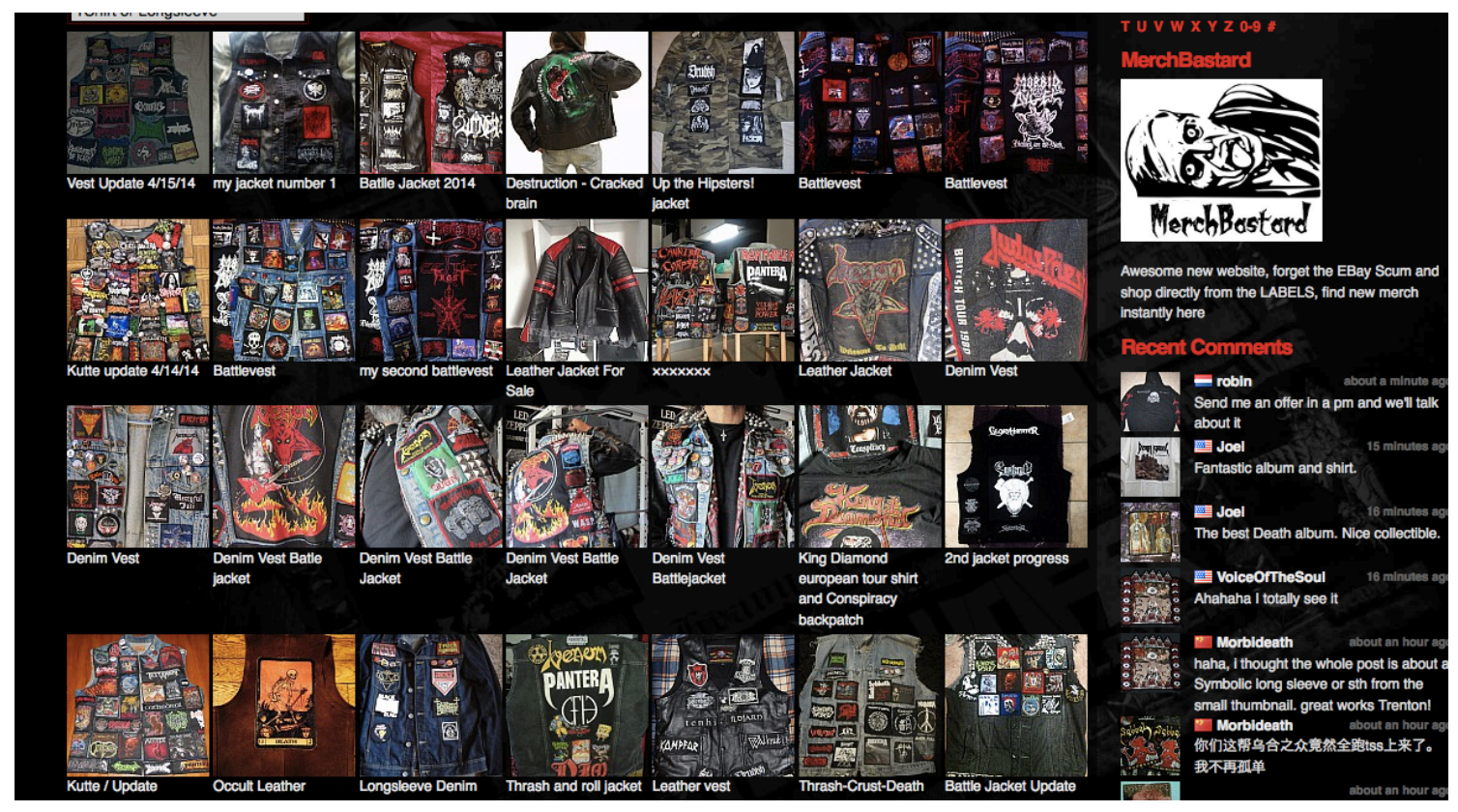

Figure 4: Battle jackets displayed on forum tshirtslayer.com

eOdy $\begin{gathered}\text { shop by } \\ \text { category }\end{gathered}$

All Cate

< Back to previous page | Listed in category: Music > Music Memorabilla > Metal > Badges/ Patches/ Stickers

IRON MAIDEN / HEAVY METAL PATCH / THE NUMBER OF THE BE,
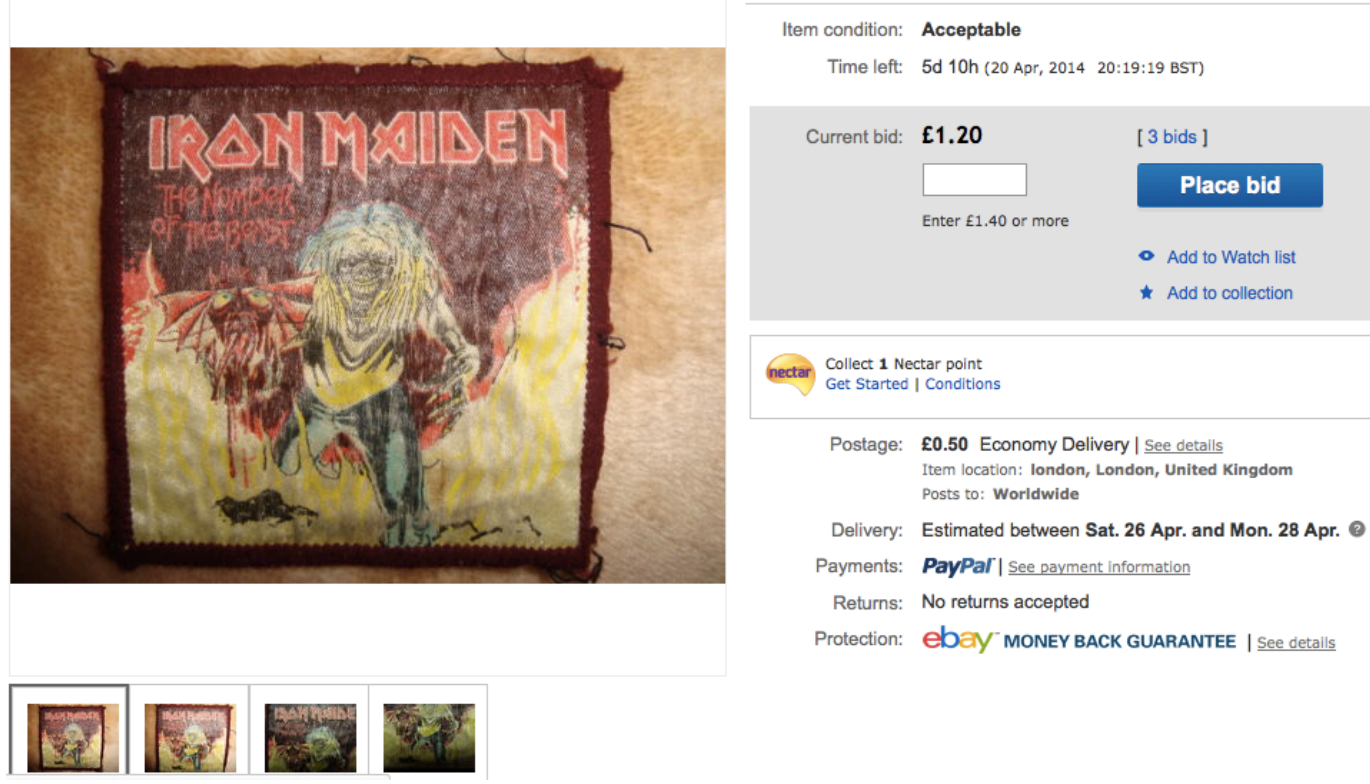

Figure 5: Iron Maiden patch for sale on ebay.co.uk 
Tom Cardwell, University of the Arts London Metal Music Studies 3.3

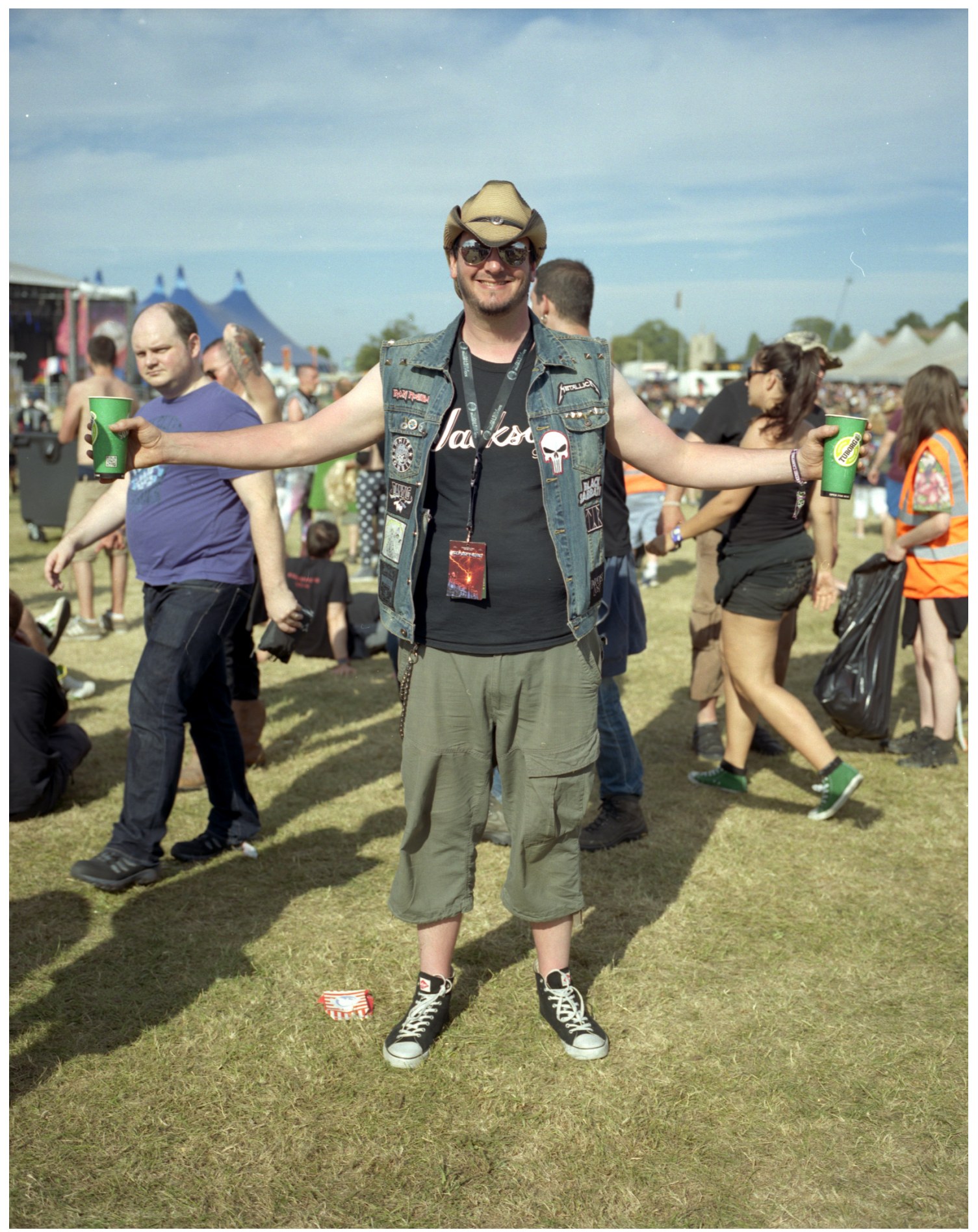

Figure 6: Paul wearing his battle jacket. Sonisphere festival, Knebworth, United Kingdom, 04.07.14. Photograph by Jon Cardwell. 
Alex, a metal fan living in New Zealand also emphasizes the individual meaning of her jacket and its personal associations: 'This is a personal thing. You can't go and buy a jacket like this. And why would you, if you could? 'Cause, it doesn't make sense' (Alex, 2014: 4, grammar unchanged).

For many if not all fans, there is a clear link between musical taste and identity, or a sense of autobiography through music. The displaying of band logos and artwork can be viewed as a kind of 'conspicuous consumption' (Veblen, 2005) through which individuals seek to assert their status within the subculture and gain subcultural capital (Thornton, 1995). Whilst there may be an awareness of peer approval in selection of band patches, particularly in online communities (Ferrarese, 2015: 200), many fans stress personal choice and a charting of their listening tastes as primary factors. When asked about the choice of patches for her jacket, Alex responded that it featured 'all bands I love, I just want to represent those bands when I'm out and about' (Alex, 2014: 1, grammar unchanged). Perhaps inevitably however, these preferences will to some extent be influenced by the opinions of peers, the metal media and trends within metal music.

Sometimes particular patches will have significance because of when or where they were acquired, or the period in the fan's life when they began listening to a certain band. In this sense the jacket may be used to chart life experiences as well as taste. Tony explained how he had recently created a new jacket to replace an old one that had worn out. He described how several patches had been transferred from jacket to jacket as they had particular significance for him:

I had an old, old 'AC/DC' badge on there l've had to replace, so that one's only about five years old. The 'Alice Cooper' one is relatively new...the 'Almighty' one's off my old jacket. So that patch is over twenty years old, as is the 'Wolfsbane' one. The 'Skid Row' one's off my old jacket. Erm, the 'Volbeat' one's new, 'Airbourne' one's new. But the 'Slash' one, I actually found that one, I've just had my girlfriend move in with me, and I was clearing out a load of drawers and I found it at the bottom of the drawer. I didn't even know I had it so I thought l'd stick it on, why not? (Tony, 2014: 4, grammar unchanged).

For Tony, the older patches transferred from one jacket to another connect the extent of his experience and history as a metal fan, whilst the most recent 'Slash' patch is connected in his mind with a positive life change - the strengthening of his relationship with his girlfriend. In a related way, Paul identifies a particular Metallica patch on his jacket with an early concert experience that left a lasting impression on him: 'Metallica, probably one of the first bands I ever saw. I sneaked into the concert and that when I was fifteen - 'cause I was tall I could get away with it.' (Paul, 2014: 3, grammar unchanged). 
The sense of personal identity is very directly expressed in the visual and material nature of the battle jacket. The jacket is worn close to the body, usually over but sometimes also under other clothing (Mal TV, 2013). For many fans, the jacket is worn most of the time, and so represents a constant wardrobe feature even as they change other items of clothing. The fact that (for most fans) the patches have been sewn on by the wearer underlines through material practice the connection of the jacket to personal identity. In some instances, jackets will feature hand painting or embroidery, representing an even greater investment of personal time and skill.

\section{Authenticity}

Rhetoric of authenticity abounds in subcultural discourse, from the endless arguments over who is 'more punk' in the American magazine Maximum Rock'n'Roll to the online debates between extreme metal fans as to what constitutes 'trve' or 'kvlt'. The autobiographical function of the battle jacket is closely tied to such a negotiation of authenticity. Within many subcultures there is an emphasis on being 'real' or authentic that is fundamental to an individual's sense of identity and standing within the peer community. If Hebdige (1979) first adapted the term 'bricolage' (from Claude Lévi-Strauss) in relation to the mixing of sartorial styles in subcultures since the 1950s, Ted Polhemus' survey of Street Style (1994) shows how eclectic these combinations can be, and how important personal appearance is to the communication of subcultural values. Hebdige recognized the importance of the contested relationship between style and substance, arguing that style was 'profoundly superficial' as he believed it could not directly effect social change (Hebdige, 1979: 17). In a contemporary world of post-subcultures (to use Muggleton's term) such distinctions are not always so clear-cut. David Chaney (2004) argues that in postmodernity subcultural distinctions, along with those of the so-called 'mainstream', are irreversibly fractured 'into a plurality of lifestyle sensibilities and preferences' (Chaney, 2004: 47).

For the post-subculturalist then, personal choices about clothing and style are just that, personal. They may or may not reflect deeper commitment to subcultural values and behaviours (Muggleton, 2000: 75). However, as has been argued earlier, some groups such as metal fans might prove to be exceptions to this post-subcultural rule. During his extensive participantobserver research into New York City bicycle messengers, Jeffrey Kidder drew distinctions between those for whom being a messenger was just a job, and those he terms 'lifestyle messengers' (Kidder, 2005: 349). For this latter group of messengers, a distinct subcultural style - a bricolaged mix of cycle gear, baggy work wear and military surplus clothes, often repaired by hand was interwoven with a distinct set of practices including flouting traffic laws and riding recklessly, refusing helmets and favouring brakeless track bikes. For Kidder, 'if action and meaning are in fact intertwined, then sociology cannot separate style from the social practices that create it.' (Kidder, 2005: 348). In a related way, the meanings carried by battle jackets are inextricably 
connected with actions - both those actions involved in their construction, and the actions performed by the fan whilst wearing the jacket (such as headbanging, moshing etc.).

Arguments about authenticity in metal style (as in any subculture) are hugely complicated by the effects of commodification and the commercial diffusion of the metal 'look'. John Clarke observed the ways in which subcultural styles are appropriated and assimilated by the fashion system which turns them from 'lifestyles' to 'consumption styles' (Clarke, 1976: 188). The effect of this on subcultural participants might be to increase their concern with being authentic, defining themselves in opposition to those from outside the subculture who appropriate elements of the style because it suits current fashion tastes. In her research into American punks in the 1980s, Kathryn Fox used an objectivist model of status hierarchies to group them into two groups of 'real punks' and 'pretenders'. She further grouped the real punks into three ranked strata of 'hardcore punks', 'softcore punks' and 'preppie punks' (Fox, 1987, in Williams, 2011: 135). Drawing on Pierre Bourdieu's theory of 'cultural capital', Sarah Thornton looked at how authenticity was negotiated in the production and consumption of dance music in the 1990s - both in terms of the records themselves, and the dance styles they facilitated. Thornton describes how authenticity is manifested through a process of 'enculturation' (Thornton, 1995: 85), and developed Bourdieu's term into the idea of subcultural capital. Subcultural capital is acquired and manifested through numerous practices and behaviours, and objectified through clothing and consumption. Authenticity is key to the construction of identity through subcultural capital:

Nothing depletes capital more than the sight of someone trying too hard. For example, fledgling clubbers of fifteen or sixteen wishing to get into what they perceive as a sophisticated dance club will often reveal their inexperience by over-dressing or confusing 'coolness' with the exaggerated cold blank stare (Thornton, 1995: 12).

The inference here might be that for those who are really embedded in the scene in question, the true revelation of authentic identification is in knowing not to try too hard, and how this might be revealed. Nicola Allett (2013) uses the idea of subcultural capital in her enquiry into notions of 'connoisseurship' amongst extreme metal fans:

The connoisseur exhibits knowledge and mastery of a subject. Likewise my respondents had thorough knowledge and expertise related to extreme metal music and culture. Such knowledge, which included extreme metal music history, genres, underground bands, instruments, music labels, and terminologies, can be interpreted as forms of subcultural capital which, (if acquired) give status and validation to the extreme metal fan. (Allett, 2013: 172) 
Similarly, in my conversations with metal fans about their battle jackets, I was often aware of tacit distinctions being drawn between 'true' metal fans, veterans of many live concerts and festivals with detailed knowledge of more arcane bands, and those whose interest and commitment might be more at a surface or stylistic level. This differentiation could be manifested in a fan's jacket - with subtle judgements made about the choice of patches, their deployment, and the general appearance of the garment - whether it looked really lived-in or newly constructed. Amongst older metal fans particularly, there is a sense that one's battle jacket should be a genuine reflection of subcultural experience. Long-time metal fan Pete was emphatic on the importance of authentic participation in the metal scene as well as autobiographical representation when selecting patches for his jacket:

They should represent your life. And in this case my life in bands. Like the bike jackets. You only get a patch if you've done something to get it $[\ldots]$ you have to earn them by being there and getting it and saying ' $I$ was there and here's the proof!' And that's how I treat this jacket. I only put on patches of bands that I have seen live, and that's a rule. [...] 'Cause this is documenting my life and my taste in music, and consequently there's a lot of non-metal stuff on here as well, which really fucks people off! The sort of, all your 'true metal heads' go 'How can you have that next to that?!' And I say 'Because I like 'em. Got a problem?!' (Pete, 2014: 2, grammar unchanged).

For Pete, the jacket represents a material document of his long experience within metal subculture. Band patches are not chosen arbitrarily (or even just because he likes the band) but commemorate attendances at live concerts (prior to the internet, concerts were often the main outlet for sale of band patches). Pete presents his physical presence at these concerts as the ultimate authentication of his status as a true metal fan. Many other fans would share this view, as concert attendance requires commitment of time, money and perhaps long-distance travel. Alex's view corresponds with Pete's:

Most of the bands (featured on the jacket) l've seen, and the occasional one I haven't seen. I've got a 'Pantera' one, and I obviously can't see them...so l've erm, just sewn them on out of a bit of loyalty rather than anything else but...erm, it is definitely representational of my youth, of my life, yeah. (Alex, 2014: 2, grammar unchanged).

In this way, the battle jacket represents much more than just the wearer's musical taste, testifying to their lived experience as a heavy metal fan, metal being a genre that places great importance on the live concert experience and its attendant practices such as head-banging, moshing and stage-diving (Weinstein, 2000: 131, 228-229).

Pete's view of the battle jacket seems to fit with Allett's notion of connoisseurship (2013), in that appearance and substance are viewed as closely connected, and the message of the jacket appeals to a strongly- 
defined conception of correct practice (Muggleton, 2000: 34). Throughout the interview, Pete was scathing in his reference to style practices that he felt did not represent authentic commitment to metal subculture. The idea of appropriating a style for its own sake, in a way that might be thought of as postmodern (Muggleton, 2000: 77), was anathema to him:

I've seen people selling ready-made patch jackets! 'Heavy metal look jackets'! And there was one, there was this famous meme that went round the internet last year, or round Facebook, of - I can't remember who it was - leather jacket painted up with 'Suicidal Tendencies', 'Excel', all bands like that, real cool hardcore bands, and he didn't have a fuckin' clue what any of it was! His stylist had bought it and gone 'Wear that!' And that fucks me off, you know. If you're representing something, you should know what it is (Pete, 2014: 4, grammar unchanged).

Like many metalheads, Pete is deeply offended by the tendency of fashion trends to co-opt subcultural style for profit, making it temporarily fashionable and leading to widespread diffusion and adoption of a subcultural look by those outside the scene. But he is also critical of the recent tendency of (often younger) metal fans to quickly produce jackets that they have not 'earned' according to his definition:

There are people walking around here (mimics another fan) 'l've got twelve patches!' and they're sewn nice and neatly, equally spaced and they're sewn on by their mum, and it looks wrong. You know, it's got to have a bit of chaos to make it look right. I mean, obviously you're looking round at a lot of jackets this weekend, you know what I'm talking about. A lot of them are like brand-new looking jackets with brand-new patches all perfectly sewn on, with massive spaces in between and not much thought put into it (Pete, 2014: 5, grammar unchanged).

Pete clearly delineates tacitly understood criteria for two types of jackets - the authentic, which represents genuine subcultural experience (according to his definition) and the inauthentic that only attempts the appearance of a genuine jacket. This fake jacket, according to Pete, fails because the creator has not understood the unwritten rules of metal subculture relating to battle jackets. They have taken a short cut to the appearance of a long-time fan, but their fake jacket has not been earned. The authentic jacket, by contrast, is personally (if imperfectly) created and lived: 'It's just nice that you know that you made it. You created it, it's your baby!' (Pete, 2014: 5, grammar unchanged).

The sense of authenticity or being real is strongly communicated through the hand-made aesthetic of the battle jacket. Patches might be deployed in a deliberately haphazard manner (although ordered nonetheless), and prominent and uneven stitching is considered a positive feature, in contrast to most garments. Pete is critical of jackets that are 'sewn nice and neatly, 
equally spaced and they're sewn on by their mum, and it looks wrong. You know, it's got to have a bit of chaos, to make it look right' (Pete, 2014: 5, grammar unchanged). Hand-rendered logos or motifs may also be employed, perhaps painted in a self-consciously imperfect or idiosyncratic way.

The foundation of the battle jacket is the denim jacket, a garment created to be hard-wearing and functional that still carries strong connotations of blue collar labour and a utilitarian sense of honest hard work (Downey, 2014). Denim itself communicates authenticity, and the customization of the jacket heightens this sense. When jacket sleeves are removed, the edges of the arm sockets are usually left to fray, giving a distinctive sequence of trailing threads that become diffuse and white over time. This communicates a sense that the garment has been personally customized by the wearer, who does not have time or inclination to tidy it up, as they choose not to observe mainstream concerns with neatness in clothing. It may also be linked to the custom among some fans of ripping the arms off t-shirts, which Weinstein suggests might be a way of communicating physical strength and toughness (2000: 131). Whatever the origins, ripping off sleeves has become de rigueur for battle jacket wearers. John Fiske interprets the deliberate customisation and distressing of denim by the consumer as symbolic resistance against capitalism (refusal to buy new clothes) and an attempt to reclaim some power in the exchange and valuing of commodities (Fiske, 1990: 14-15).

Marks of wear such as fading, rips, holes, burns or repairs are viewed by fans as enhancing the jacket's symbolic value. An interviewee called Nick describes this process as he recalls how he began to make his jacket: 'I actually owned the jean jacket for about ten (years), and ironing on the Exodus patch came from covering a cigarette burn in the beginning, and it just kind of grew from there' (Jenna and Nick, 2015: 2). The stylised codification of such overt DIY repair and construction is similar to that observed by Kidder (2005) in the clothing of cycle messengers.

Muggleton's concept of distinctive individuality emphasises both the way in which subcultural style is used by individuals to express their personal identity, but also their identification with a wider collective group (Muggleton, 2000: 63-64). For many metal fans, the sense that they are set apart from the mainstream by their membership of the metal subculture is of great importance. As Muggleton puts it: 'Invoking a reference group enables certain individuals to emphasise their insider status as members of an esoteric, subterranean scene through self-exclusion from a larger category of uninitiated "outsiders"' (Muggleton, 2000: 63-64). For these fans, the metal tshirt or battle jacket plays an important role in identifying them to other metal fans, and in separating them from the rest of society. The battle jacket perhaps marks a greater commitment to metal than the t-shirt, as it represents a larger investment of money and time. Metal band t-shirts are also more likely to be worn as fashion items by non-metal fans, and have in recent years even been produced by leading fashion retailers to complement ranges of rock or metal style clothing. 
The sense in which the battle jacket strengthens bonds within metal communities is clear in several of the interviews I conducted. Jenna, a Canadian fan reflects:

All of my friends that go to shows (have jackets). I do have friends, one friend actually, who doesn't have a vest, but she sews patches on black hoodies. [...] I have other friends that have leather jackets that they sew... pretty much everybody that I know does something with patches [...] Even if you don't know somebody you go up to them and you're like 'Oh my god, sweet patch!' (Jenna and Nick, 2015: 6).

Another fan called Emily explains this role of the battle jacket in more depth:

Metalheads are outsiders from popular culture and the mainstream and all that, because we choose to be that way, to become part of this underground community of people. You tend to exclude the mainstream from your insider...I call it 'outsider/insider' because you're an outsider but you're inside of this outsider culture. So yes, I do think that metalheads like to wear their vests because it gives you the opportunity to meet other metalheads, because someone can see you from down the street and say 'Oh I love that patch, I want to talk to that person', because you have that connection, whereas everyone else walking around the city is not going to understand (Emily, 2015: 6).

In this way the battle jacket allows the individual to connect with the wider metal subculture, to strengthen bonds with other fans and potentially to make new friendships, based on shared appreciation of certain bands. The more niche or esoteric the band, the more likely it is to be remarked upon by another fan as the connection is considered more unusual. Indeed, displaying the logos of very obscure bands increases a fan's subcultural capital (Thornton, 1995, Allett, 2013) as they demonstrate rarefied musical tastes and specialist knowledge of metal.

A sense of community is embodied in the common form of the jacket. The way in which the cut-off denim (usually blue or black) provides a template for customization underlines a shared expression, even if particular band choices vary. The panels of the jacket provide some standard forms for patch arrangement - the large back panel lending itself to the slightly tapered rectangular back patch (manufactured to this shape in response to the design of denim jackets). The yoke across the shoulders gives a horizontal bar for placing several small patches or larger logo strip patches (not unlike the top rocker' featured on bike club jackets). The side panels allow for vertical stacking of smaller patches, whilst the waistband might feature mid-sized logo strips. The chest pockets are often decorated with circular patches, and some fans add small pin badges to the pockets and chest area of the jacket. Patch choices can also express community. The inclusion of certain iconic band 
logos or artworks on many jackets underlines connections between fans. 'Iron Maiden's 'Eddy' or 'Slayer's pentagram devices are amongst the most commonly featured.

\section{Masculinity}

The popular conception that heavy metal subcultures are male dominated or even overtly misogynistic is supported by a range of literature (for example Kahn-Harris, 2007, Walser, 1993, Weinstein, 2000). However, there are some indications that there is also a place for femininity (or at least a more nuanced masculinity) in contemporary metal scenes. Hill (2015) found from her interview research with female metal fans that women related to metal music through listening practices that 'encompassed feelings of travel, romance and transcendence and contrast with notions of the music as masculine' (Hill, 2015: 240). Overell (2013) uses an analysis of affect in the Melbourne grindcore scene to suggest that there is room for a feminized subject within this often apparently misogynistic genre.

My own research supports these suggestions that metal subcultures are becoming more diverse in terms of gender articulations. Whilst the majority of battle jacket wearers that I met and observed were male, a number of respondents were female. Whilst there are not overt differences in the nature of jackets worn by women, there are perhaps some divergences in customisation styles. Eleanor and Jemima emphasised their dislike of large backpatches (Eleanor and Jemima, 2014: 5), a view shared by other female fans whose jackets similarly featured only small patches spread across the back panel.

The image of the battle jacket is arguably masculine (indeed, the very term 'battle' is indicative) and there are clear connections to military uniform traditions. However, it is interesting that such a masculine garment relies on processes of sewing and embroidery, which traditionally have been considered feminine. Whilst some fans might get female partners to construct the jacket for them, the majority of those I interviewed emphasised the importance of doing this oneself. A parallel to this example of a masculine culture embracing sewing practices might be found once more in the military, where service personnel sew standards and uniform badges, or use quilting as an activity during convalescence after injury (Kenny, McMillan \& Myrone, 2014: 14). All this is not to say that battle jackets (like much of metal styling and imagery) are not predominantly masculine - most metal artwork refers to violence, aggression, death and morbid subjects. The denim jacket itself is closely tied to discourses of blue-collar masculinity (Fiske,1990: 5) and features such as studs and chains reinforce an ostensibly aggressive message. However, it is possible to see how more complex nuances of gender might be found in these garments.

\section{Practices of customization}


Intrinsic to the nature of battle jackets is this idea of DIY construction (in part inherited from the punk movement). These are highly physical garments, and an involvement with their material construction is key to the fan's relationship with the jacket that is in many ways viewed as symbolic of their participation in the metal scene in general. In The Craftsman (2008) Richard Sennett examines the changing role of craft practices (in the widest sense) in culture, arguing that a personal involvement with skilled making processes is important both for the individual and society. Sennett describes the importance of material consciousness, a kind of interaction with the world through things immediate to our situation: 'we become particularly interested in the things we can change' (Sennett, 2008: 120, emphasis added). The practice of customizing battle jackets might be thought of as demonstrating 'material individuality': a personal articulation of allegiance to metal subculture through the physical object of the jacket and the customization worked upon it by the fan.

Sennett's material consciousness is a useful way of thinking about the metal fan constructing their jacket. The selection of a jacket, modifying it, selecting patches and deciding where to deploy them as well as the central process of hand-stitching them on to the denim are all experiences that cannot easily be understood unless they are felt first-hand (testified to by the fans quoted earlier who emphasize the importance of making the jacket oneself). Sennett recognizes the extensive role of tacit knowledge in craft practice - skills that are not easily taught or explained - but are gained through trial and error.

In earlier examples of battle jackets from the late 1970 s and early 1980 s hand embroidery can be found in place of manufactured band patches, which it seems were not yet widely produced (Pete, 2014). Some fans who still wear their jackets from this period display a considerable amount of careful hand embroidery (see fig.3). Pete, a jacket maker since the early 1980s told me:

I could be a bit crafty and, you know, do that (embroider), and it was also cheaper, if you had massive logos on the back I could just sit there, you know, if I had the patience I could just sit there with a needle and I could do it! (Pete, 2014: 1, grammar unchanged).

It is significant here that Pete mentions both the time involved (patience) and the physical tool (needle) in his account of embroidering. Craftspeople invariably value their tools as conduits for practice, and are keenly aware of time as a measure of labour. Conversely, the products of craft might also be thought of as reifications of time spent, physical agglomerations of intangible hours. Embroidery is particularly time consuming, and was historically used to pass leisure hours in domestic settings, or to occupy the hands and thoughts of convalescing or inactive service personnel (Kenny, McMillan \& Myrone, 2014). The practice of embroidering on battle jackets represents a deep personal investment in metal music, with the fan's loyalty displayed publicly 
but also marked privately through the time expended in customization. It is also notable as an example of embroidery (often stereotyped as a feminine occupation) practiced by men, in what has been noted as a predominantly white, male, working class subculture (Weinstein, 2007).

Whilst hand-painted designs on jackets are not as common amongst metal fans as they are in some other subcultures (e.g. punk and goth), they can be found on some jackets, particularly as a way of creating patches for bands that could not be found for sale. Some fans have designs painted directly onto the jacket itself, as well as some who have painted onto pieces of fabric and then stitched these on like a woven patch. An example of the latter practice can be seen again on Pete's jacket (see fig.7). This is a patch created by hand using acrylic paint representing the band 'Gong' (see fig.8). When interviewed, Pete was very proud of this patch, in part due to the intricacy of the design and how faithfully it represents the band's artwork. He described the process of painting the patch: 'I went down to a...what was it?...a 00000 sable brush! And thinned the paint down and I actually managed to get the lines in, that's hand brushed! That took me hours!' (Pete, 2014: 2).
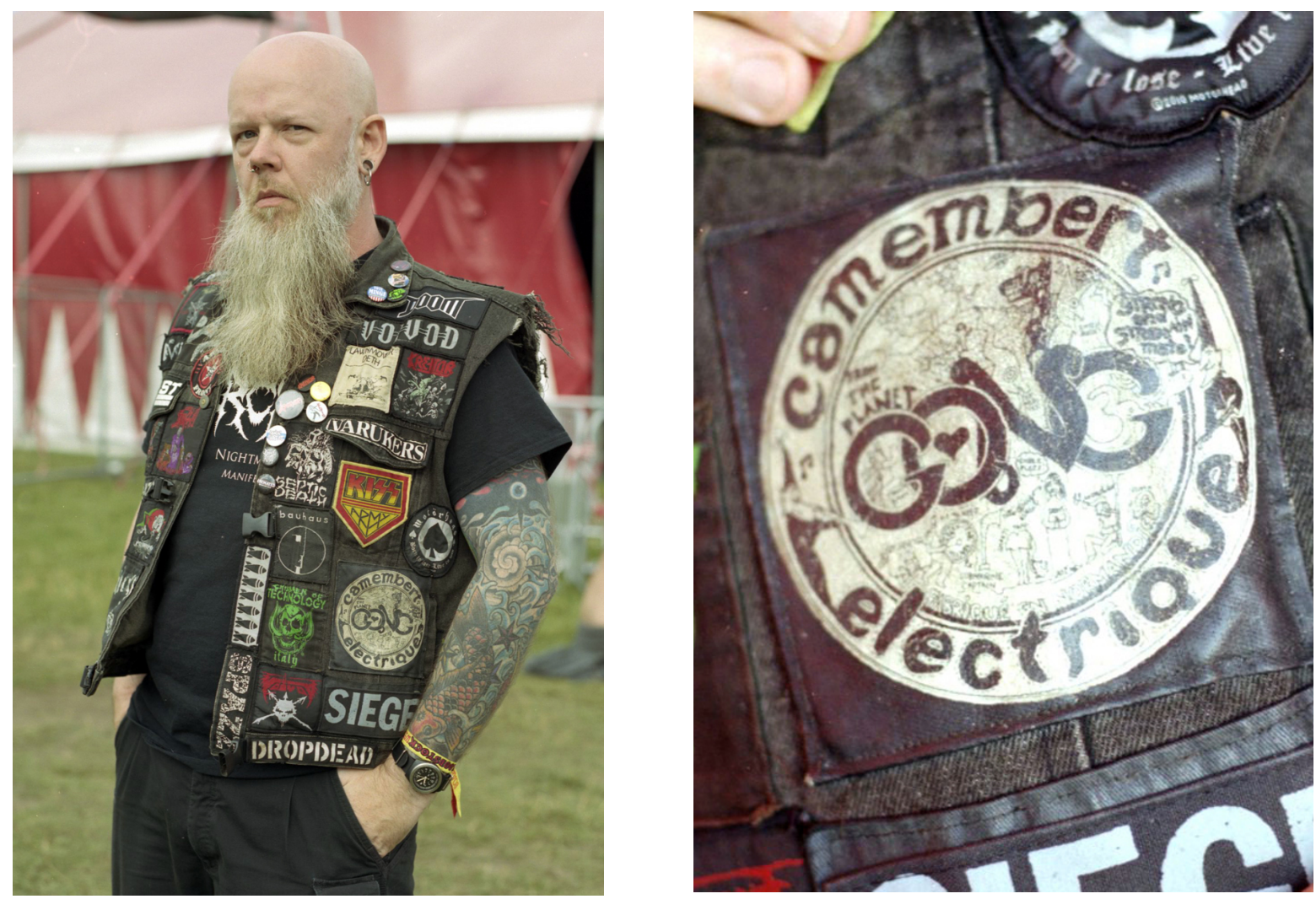

Figures 7 and 8: Pete with his jacket and detail showing hand-painted Gong patch. Bloodstock festival, Derbyshire, United Kingdom, 09.08.14. Photographs by Jon Cardwell

Jeanie Finlay's documentary Sound It Out (2011) portrays an independent record shop in the north of England and profiles some of its regular customers. Part of the film focuses on two metal fans, Sam and Gareth, who 
talk about making their battle jackets. Gareth has a jacket featuring a handmade back patch for the band 'Pisschrist'. He comments 'This back patch took me three hours to stencil and paint' (Finlay, 2011). Once more the importance to the maker of the time spent in producing the patch is a major part of its significance and value to him. As with Pete's patch, Gareth's stencilled work closely represents a pre-existing artwork for his chosen band, rather than his own invention. Amongst many streams of craft and folk art practice it is often the case that the goal of the practitioner is to closely reproduce accepted forms or archetypes, with innovation occurring gradually and collectively rather than individually (Sennett, 2008).

As well as hand painting, a more common method of making patches where manufactured bands are unobtainable is to cut out designs on band t-shirts. Occasionally, some fans might even screenprint their own patches, based on band logos. The use of these custom patches might be due to size requirements, for example if a larger back patch is required than the stock commercial sizes, or if the design in question is not available as a patch. A jacket maker called Chris cited several of these motives for making his custom 'Alice Cooper' back patch:

I made the back patch myself [...] It's an old shirt that I had from the 2007 tour. I just couldn't find any back patches at a decent price that I liked. They were all weird shapes. So I just bit the bullet, cut it up and stuck it on (Chris, 2014: 3).

These various craft-based processes are used by fans to produce battle jackets that are inherently personal items. The investment of time in making is emblematic of a heartfelt commitment to metal subculture for many, and whilst opinions might differ as to what constitutes 'correct' or genuine jacket practice and style, few jacket wearers seem to be merely appropriating the style for its own sake. In this sense it is argued that battle jackets are interwoven with the rhetoric of authenticity that correlates with wider discourses in metal subcultures.

\section{Summary: 'material individuality'}

Battle jackets are extremely important to metal fans, both as markers of membership of the metal subculture and as visual expressions of a sense of personal identity constructed through musical taste. The jackets are constructed and 'read' by other fans in terms of complex symbolic codes that relate to identity and authenticity. Whilst the extent to which battle jackets represent a deeper commitment to metal (rather than just a style choice) varies between fans, on the whole they tend to mark a greater level of engagement than might be expected from wider post-subcultural trends. It is through the visual and material aspects of the jackets that these ideas are embodied and demonstrated. It is important to consider the meaning of both the craft and DIY practices involved in the making of battle jackets as well as 
the finished articles in understanding their significance to metal fans as well as the wider culture.

An argument for the importance and symbolic functions of battle jackets has been outlined in relation to Muggleton's idea of distinctive individuality, as well as Thornton's subcultural capital and Sennett's material consciousness. The term material individuality is proposed as a way of referring to these ideas, and to underline the ways in which the battle jacket reifies them in a material form. 


\section{Bibliography}

Alex. (2014) Interview with Alex. Interviewed by Tom Cardwell, $5^{\text {th }}$ July.

Alford, S. \& Ferriss, S. (2008) Motorcycle. London: Reaktion Books.

Allett, N. (2013) 'The Extreme Metal 'Connoisseur', in Hjelm, T., Kahn-Harris, K. and LeVine, M. (eds.) Heavy Metal: Controversies and Countercultures. London: Equinox. pp.166-181.

Baka, A. (2015) 'The Forming of a Metalhead: Constructing a Subcultural Identity', in Karjalainen, T. \& Karki, K. (eds.) Modern Heavy Metal: Markets, Practices and Cultures. Aalto: Aalto University, pp.55-63.

Chris. (2014) Interview with Chris. Interviewed by Tom Cardwell, $9^{\text {th }}$ August.

Chaney, D. (2004) 'Fragmented Culture and Subcultures.' in Bennett, A. \& Kahn-Harris, K.

(eds.) After Subculture: Critical Studies in Contemporary Youth Culture. Basingstoke, UK:

Palgrave, pp. 36-48.

Clarke, J. (1976) 'Style', in Hall, S. \& Jefferson, T. (eds.) Resistance Through Rituals. London: Routledge, pp.175-191.

Downey, L. (2014) A Short History of Denim. Available at: http://www.levistrauss.com/wpcontent/uploads/2014/01/A-Short-History-of-Denim2.pdf (Accessed 11th August 2015).

Dulaney, W. (2005) 'A Brief History of "Outlaw" Motorcycle Clubs', International Journal for Motorcycle Studies, 1(3), np.

Eleanor and Jemima. (2014) Interview with Eleanor and Jemima. Interviewed by Tom Cardwell, $5^{\text {th }}$ July.

Emily. (2015) Interview with Emily. Interviewed by Tom Cardwell, $7^{\text {th }}$ June.

Erikson, E. (1959). Identity and the Life Cycle. Madison, CT: International Universities Press.

Ferrarese, M. (2015) 'Heavy Metal Nothingness: Alluring Foreignness and Authenticity Construction in Early 2010s Malaysian metal', in Karjalainen, T. \& Karki, K. (eds.) Modern Heavy Metal: Markets, Practices and Cultures. Aalto: Aalto University, pp.195-205.

Finlay, J. and Hodgson, S. \& Finlay, J. 2011. Sound It Out [Motion picture]. UK: Glimmer Films.

Fiske, J. (1990) Understanding Popular Culture. London: Routledge.

Friedrichs, H. (2012) Pride and Glory: The Art of the Rockers' Jacket. DAAB Media.

Grimshaw, A., and Ravetz, A. (2005) Visualising Anthropology. Bristol: Intellect.

Grimshaw, A., Owen, E. and Ravetz, A. (2010) 'Making Do: The Materials of Art and Anthropology', in Schneider, A. and Wright, C. (eds.) (2010) Between Art and Anthropology: Contemporary Ethnographic Practice. Oxford: Berg, pp. 147-162.

Hebdige, D. (1979) Subculture: The Meaning of Style. London: Routledge.

Hill, R. L. (2015) 'Using Women's Listening Pleasure to Challenge the Notion of Hard Rock and Metal as 'Masculine' Music, in Karjalainen, T. \& Karki, K. (eds.) Modern Heavy Metal: Markets, Practices and Cultures. Aalto: Aalto University, pp.240-246.

Jenna and Nick. (2015) Interview with Jenna and Nick. Interviewed by Tom Cardwell, $8^{\text {th }}$ June.

Kahn-Harris, K. (2007) Extreme Metal: Music and Culture on the Edge. Oxford: Berg.

Kenny R., McMillan, J. \& Myrone, M. (2014) British Folk Art. London: Tate Enterprises Ltd. Kidder, J. (2005) 'Style and Action: A Decoding of Bike Messenger Symbols', Journal of Contemporary Ethnography, 34(2), pp. 344-367.

Mal TV (2013) Alt Life: Cut-Off Denim Jackets. Available at:

https://www.youtube.com/watch?v=3XIRKX1KeX4 (Accessed: $11^{\text {th }}$ August 2015).

Muggleton, D. (2000) Inside Subculture; The Postmodern Meaning of Style. Oxford: Berg.

Overell, R. (2013) ' '[l] Hate Girls and Emo[tions]': Negotiating Masculinity in Grindcore Music, in Hjelm, T., Kahn-Harris, K. and LeVine, M. (2013) Heavy Metal: Controversies and Countercultures. London: Equinox, pp. 201-227.

Paul. (2014) Interview with Paul. Interviewed by Tom Cardwell, $4^{\text {th }}$ July.

Pete. (2014) Interview with Pete. Interviewed by Tom Cardwell, $9^{\text {th }}$ August.

Polhemus, T. (1994) Street Style; From Sidewalk to Catwalk. London: V\&A Publications.

Sennet, R. (2008). The Craftsman. London: Penguin.

Stuart, J. (1987) Rockers!. Plexus, London. 
Tom Cardwell, University of the Arts London

Metal Music Studies 3.3

Stubberud, J., Strømmen, S. \& Belgaux, C. (2016) Death Archives: Mayhem 1984-94.

London: Ecstatic Peace Library.

Thornton, S. (1995) Club Cultures : Music, Media and Subcultural Capital. Cambridge: Polity Press.

Tony. (2014) Interview with Tony. Interviewed by Tom Cardwell, $4^{\text {th }}$ July.

T-shirt Slayer (no date) Available at: http://www.tshirtslayer.com (Accessed 05 January 2015)

Veblen, T. (2005) Conspicuous Consumption. London: Penguin.

Vick, K. (2015) 'Roots of a Biker Battle', Time (June 1, 2015), p.10.

Walser, R. (1993) Running with the Devil: Power, Gender and Madness in Heavy Metal

Music. Hannover, NH: University Press of New England.

Weinstein, D. (2000) Heavy Metal: The Music and Its Culture. Boston, MA.: DeCapo Press.

Weinstein, D. (2007). Heavy Metal's Proud Pariahs. In A. Greenberg (Ed.), Youth

Subcultures: Exploring Underground America. New York: Pearson Longman.

Williams, J. (2011) Subcultural Theory. Cambridge: Polity Press. 